\title{
PERSEPSI PASANGAN USIA SUBUR (PUS) TENTANG KELUARGA BERENCANA (KB) DI WILAYAH PESISIR PANTAI KECAMATAN PARIAMAN UTARA KOTA PARIAMAN
}

\author{
Maisyaqinah $^{1}$, Yurni Suasti ${ }^{2}$, Rery Novio $^{2}$ \\ Program Studi Pendidikan Geografi \\ Fakultas Ilmu Sosial, Universitas Negeri Padang \\ Email maisyaqinah@gmail.com
}

\begin{abstract}
Abstrak
Penelitian ini bertujuan untuk mendeskripsikan persepsi Pasangan Usia Subur (PUS) tentang Keluarga Berencana (KB) berdasarkan tingkat pendidikan, umur, pekerjaan dan pendapatan di Wilayah Pesisir Pantai Kecamatan Pariaman Utara Kota Pariaman. Jenis penelitian ini adalah deskriptif dengan pendekatan kuantitatif. Populasi pada penelitian ini adalah seluruh PUS yang berada di Wilayah Pesisir Pantai Kecamatan Pariaman Utara Kota Pariaman. Sampel diambil dari dua desa yang berada di Wilayah Pesisir Pantai Kecamatan Pariaman Utara Kota Pariaman yaitu Desa Naras I dan Desa Padang Birik-Birik dengan jumlah keseluruhan sebanyak 71 responden. Hasil penelitian menemukan bahwa ada beda secara signifikan persepsi PUS tentang KB berdasarkan tingkat pendidikan. Yang artinya tingkat pendidikan dapat mempengaruhi persepsi PUS tentang KB, semakin tinggi tingkat pendidikan, semakin positif persepsi PUS tentang KB. Sedangkan dilihat pada umur, pekerjaan dan pendapatan ditemukan tidak ada beda secara signifikan persepsi PUS tentang KB. Yang artinya umur, pekerjaan dan pendapatan tidak mempengaruhi persepsi PUS tentang KB.
\end{abstract}

Kata Kunci: Persepsi, Pasangan Usia Subur (PUS) dan Keluarga Berencana (KB)

\begin{abstract}
This purpose of this reaserch is to describe the perception of fertile age couples (PUS) on family planning (KB) based on education level, age, occupation and income in the Coastal Zone of North Pariaman District, Pariaman City. Type of research is quantitative descriptive. Population in this study were all PUS in the Coastal Areas of North Pariaman District. Samples were taken from Naras I Village and Padang Birik-Birik Village with 71 respondents. The results of the study found that there were significant differences in PUS perceptions of KB based on education level. Which means that education level can influence perceptions of PUS about KB, the higher the education, the more positive perceptions of PUS about KB. Whereas seen at age, occupation and income found there was no significant difference in perception of PUS about KB. Which means that age, work and income do not affect the perception of PUS about KB.
\end{abstract}

Keywords: Perception, fertile age couples (PUS) and family planning (KB)

\footnotetext{
${ }^{1}$ Mahasiswa Program Studi Pendidikan Geografi

${ }^{2}$ Dosen Jurusan Geografi Fakultas Ilmu Sosial Universitas Negeri Padang
} 


\section{PENDAHULUAN}

Keluarga Berencana (KB) merupakan salah satu program dari pemerintah untuk menekan laju pertumbuhan yang masih tinggi. Menurut UU no 52 tahun 2009, KB merupakan upaya mengatur kelahiran anak, jarak dan usia ideal melahirkan, mengatur kehamilan, melalui promosi, perlindungan dan bantuan sesuai hak reproduksi untuk mewujudkan keluarga yang berkualitas.

Selanjutnya menurut Suratun $d k k$ (2008), KB sebagai suatu usaha yang mengatur banyaknya kehamilan sedemikian rupa sehingga berdampak positif bagi ibu, bayi, ayah serta keluarganya yang bersangkutan tidak akan menimbulkan kerugian sebagai akibat langsung dari kehamilan tersebut.

Menurut Islam, KB yaitu merencanakan jumlah keturunan semaksimal mungkin dengan tetap memperhatikan jarak kelahiran sesuai syariat (Anton, 2008). Abdurrahman Abdullah al Farisyi (Rosyadi, 1993) mengatakan bahwa pembatasan kehamilan itu hukumnya haram, apabila didasarkan takut kepada kefakiran dan takut tidak kebagian rezeki. Sebab yang demikian bertentangan dengan ayat-ayat Al-Quran. Selanjutnya ia mengatakan bahwa pembatasan kelahiran itu boleh hukumnya apabila keluarga yang bersangkutan khawatir akan adanya kemadharatan dalam kesehatan anak dan ibunya.

$\begin{array}{ccr}\text { Suasti dan Mariya } & \text { (2017) } \\ \text { menyebutkan } & \text { tujuan dari adanya }\end{array}$

kebijakan KB ini adalah untuk mengendalikan pertumbuhan penduduk melalui usaha penurunan tingkat kelahiran. Selanjutnya Sulistyawati, (2011) juga menjelaskan bahwa tujuan dengan adanya program KB ini adalah pengatur kelahiran, pendewasaan usia perkawinan, peningkatan ketahanan dan kesejahteraan keluarga. Pelaksanaan KB dapat ditingkatkan apabila masyarakat memiliki persepsi yang positif. Karena Persepsi masyarakat terhadap suatu hal tertentu merupakan landasan bagi timbulnya kesediaan untuk ikut terlibat dan berperan aktif. Makna positif atau negatif sebagai hasil persepsi akan menjadi pendorong atau penghambat jalannya suatu kegiatan. Seperti penelitian yang telah dilakukan oleh Wulandari (2008) di Desa Panggungharjo, Kecamatan Sewon, Kabupaten Bantul tentang persepsi dan patisipasi masyarakat terhadap program $\mathrm{KB}$, menemukan bahwa masyarakat, tokoh masyarakat maupun ahli kesehatan memiliki persepsi yang positif terhadap KB sehingga partisipasi mereka juga tinggi dalam ber KB.

Partisipasi masyarakat selain dilihat dari angka partisipasi dalam KB itu sendiri, juga dapat dilihat dari tinggi atau rendahnya angka fertilitas total atau total fertility rate (TFR) dan angka pravelensi kontrasepsi (contraceptive prevalence rate/CPR). TFR yang tinggi dan CPR yang rendah bisa jadi menunjukkan angka partisipasi masyarakat yang rendah dalam ber KB, Senada dengan yang disampaikan oleh Suarni dan Mariya (2017) bahwa CPR menunjukkan tingkat kesadaran masyarakat dalam ber KB, antara TFR 
dengan CPR saling berhubungan, dimana semakin tinggi TFR pada suatu daerah semakin rendah CPR nya. Seperti yang terjadi di Provinsi Sumatera Barat.

Sumatera Barat dilihat dari CPR dan TFR dapat dikatakan bahwa partisipasi masyarakat dalam ber $\mathrm{KB}$ masih rendah. Berdasarkan data BKKBN oleh Siregar (2016), angka CPR Sumatera sebesar 51,3 (rendah) dengan TFR sebesar 2,79 (tinggi). Menurut wakil gubernur Sumatera Barat Nasrul Abit, daerah dengan angka kelahiran tinggi ditemukan di daerah pesisir pantai sehingga menjadi sasaran utama KB (Harianhaluan, 2016).

Salah satu wilayah pesisir pantai di Sumatera Barat adalah Kota Pariaman khususnya Kecamatan Pariaman Utara. Dari tahun 2014-2016 di kecamatan ini ditandai dengan penurunan CPR yang tinggi. Tahun 2014 angka CPR sebesar 68,68\%, tahun 2015 angka CPR sebesar 60,17\% dan tahun 2016 CPR terjadi penurunan yang cukup signifikan menjadi 40,34\% (BPS Kota Pariaman dalam Angka, 2017 dan UPTB.PKB Kecamatan Pariaman Utara, 2017). Penurunan ini bisa terjadi karena persepsi masyarakat terutama Pasangan Usia Subur (PUS) tentang KB yang berbeda. Senada yang dipaparkan oleh Wood (2013) dan Mulyana (2016) bahwa persepsi seseorang dipengaruhi oleh faktor biologis seperti rasa lapar dan haus; faktor fisiologis seperti tinggi badan, dan kesehatan; faktor sosial budaya seperti gender, agama, umur, tingkat pendidikan dan pengetahuan, pekerjaan, penghasilan, peranan, status sosial, pengalaman masa lalu, kebiasaan, kepercayaan, nilai, sikap, dan bahkan faktor-faktor psikologis seperti kemauan keinginan, motivasi, pengharapan, kemarahan, kesedihan, dan sebagainya. Hal ini sejalan dengan pernyataan Bapak Joni Alfian selaku Koordinator KB di Kecamatan Pariaman Utara yang mengatakan bahwa salah satu penyebab turun naiknya jumlah aksepstor KB karena sudut pandang PUS terutama seorang istri karena seorang istri pada umumnya menggunakan KB. Oleh karena itu, penulis tertarik melakukan penelitian lebih lanjut dengan melihat persepsi PUS khususnya seorang istri tentang KB di Desa Naras I dan desa Padang Birik -Birik Kecamatan Pariaman Utara, dengan judul "Persepsi Pasangan Usia Subur tentang Keluarga Berencana (KB) di Wilayah Pesisir Pantai Kecamatan Pariaman Utara, Kota Pariaman"

\section{METODE PENELITIAN}

Jenis penelitian ini yaitu penelitian deskriptif kuantitatif. Populasi penelitian ini adalah seluruh PUS yang berada di Wilayah Pesisir Pantai Kecamatan Pariaman Utara dengan jumlah 575 PUS (UPTB.PKB Kecamatan Pariaman Utara, 2017). Sampel responden diambil di dua daerah sampel yakni Desa Naras 1 sebanyak 38 responden dan Desa Padang Birik-Birik sebanyak 33 responden menggunakan simple random sampling dengan rumus Slovin. (Siregar, 2013) 


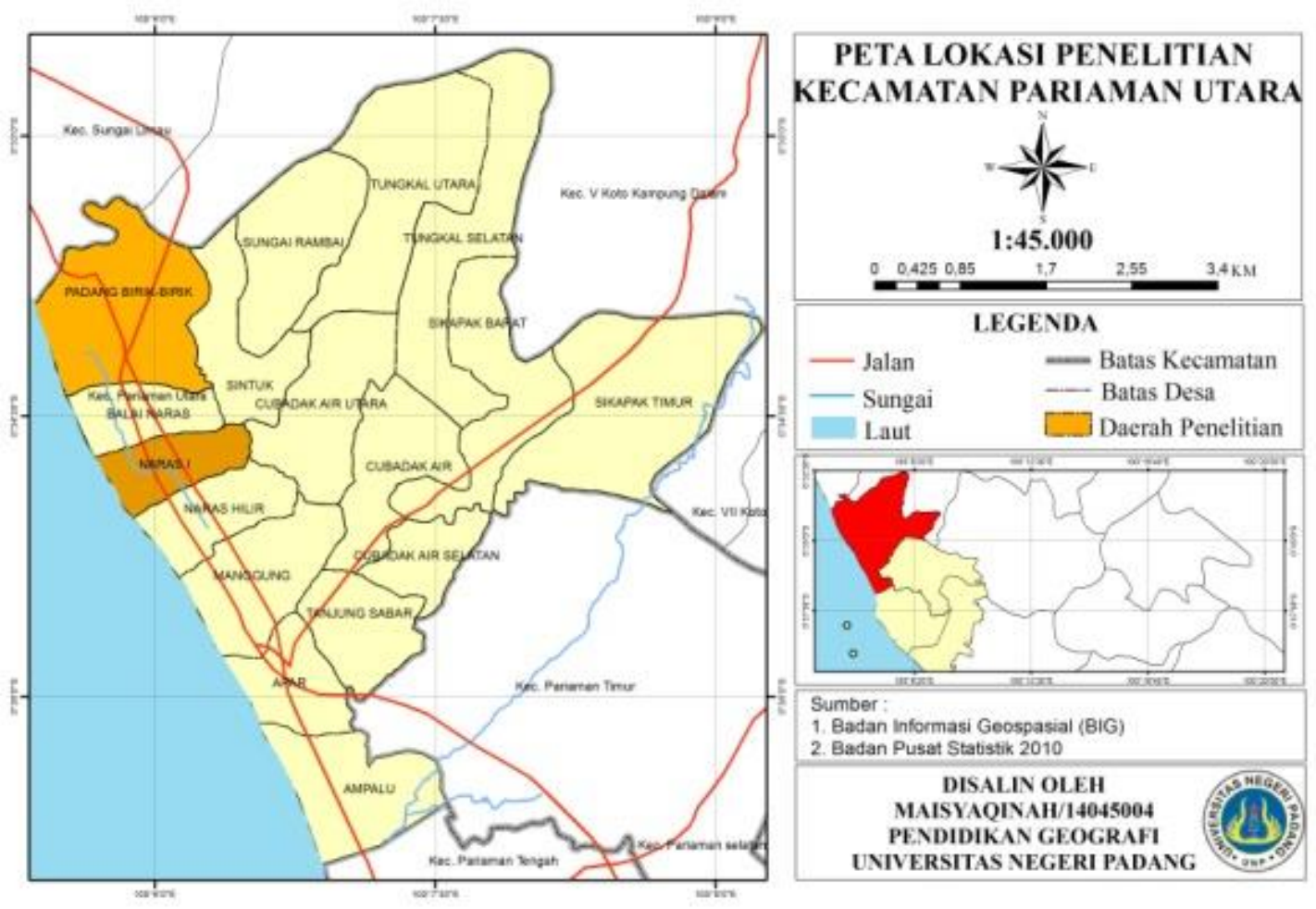

Gambar 1. Peta Wilayah Penelitian

\section{HASIL DAN PEMBAHASAN}

Persepsi PUS tentang KB dalam penelitian ini dilihat berdasarkan tingkat pendidikan, umur, pekerjaan dan pendapatan PUS di Wilayah Pesisir Pantai Kecamatan Pariaman Utara Kota Pariaman.

\section{Persepsi PUS tentang KB Berdasarkan Tingkat Pendidikan}

Tingkat pendidikan dalam penelitian ini yaitu tingkat pendidikan istri dari PUS yang dikelompokkan menjadi tiga jenjang pendidikan yaitu jenjang pendidikan dasar (SD-SMP sederajat), jenjang pendidikan menengah (SMA sederajat) dan jenjang pendidikan tinggi (diploma-sarjana) (UU Nomor 20 Tahun 2003).

Tabel 1. Persepsi PUS tentang KB Berdasarkan Tingkat Pendidikan.

\begin{tabular}{|c|c|c|c|c|c|c|}
\hline \multirow{3}{*}{$\begin{array}{c}\text { Tingkat } \\
\text { Pendidikan }\end{array}$} & \multicolumn{4}{|c|}{ Persepsi PUS } & \multicolumn{2}{|c|}{ Frekuensi } \\
\hline & \multicolumn{2}{|c|}{ Positif } & \multicolumn{2}{|c|}{ Negatif } & \multirow{2}{*}{ f } & \multirow{2}{*}{$\%$} \\
\hline & Frekuensi & $\%$ & Frekuensi & $\%$ & & \\
\hline Pendidikan Dasar & 8 & 11,27 & 20 & 28,17 & 28 & 39,44 \\
\hline Pendidikan Menengah & 24 & 33,80 & 12 & 16,90 & 36 & 50,70 \\
\hline Pendidikan Tinggi & 6 & 8,45 & 1 & 1,41 & 7 & 9,86 \\
\hline Jumlah & 38 & 53,52 & 33 & 46,48 & 71 & 100 \\
\hline$X^{2}$ & & & & & & 12,4211 \\
\hline$X_{0,05 ; 2}$ & & & & & & 5,991 \\
\hline
\end{tabular}

Sumber: Pengolahan Data Primer, 2018. 
Data Tabel 1 memperlihatkan bahwa persepsi PUS tentang KB cukup bervariasi. Setelah dilakukan uji statistik menggunakan chi-square dengan hasil $X^{2}$ hitung $12,4211>X^{2}$ Tabel 5,991, ternyata persepsi PUS tentang $\mathrm{KB}$ berdasarkan tingkat pendidikannya menunjukkan perbedaan yang signifikan. Artinya makin tinggi tingkat pendidikan PUS maka ada kecenderungan persepsi PUS tentang $\mathrm{KB}$ makin positif.

Temuan ini senada dengan yang dilakukan oleh Setiyawan (2015) dalam kajiannya yang berjudul Hubungan antara tingkat pendidikan dengan persepsi para suami tentang Program
Keluarga Berencana di RW. 03, Bintara 8, Kelurahan Bintara, Kecamatan Bekasi Barat, Kota Bekasi bahwa semakin tinggi tingkat pendidikan para suami, semakin positif pula persepsinya tentang KB.

\section{Persepsi PUS Tentang KB Berdasarkan Umur}

Umur PUS dalam penelitian ini yaitu umur istri dari PUS yang dikelompokkan menjadi 3 kelompok umur yaitu 20-29 tahun, 30-39 tahun dan 40-49 tahun.

Tabel 2. Persepsi PUS tentang KB dari Berdasarkan Umur.

\begin{tabular}{lrrrrrr}
\hline \multirow{2}{*}{ Usia } & \multicolumn{3}{c}{ Persepsi PUS } & \multicolumn{3}{c}{ Frekuensi } \\
\cline { 2 - 5 } & \multicolumn{2}{c}{ Positif } & \multicolumn{2}{c}{ Negatif } & \multirow{2}{*}{ Frekuensi } & \multicolumn{1}{c}{$\%$} \\
\cline { 2 - 5 } & \multicolumn{1}{c}{ Frekuensi } & \multicolumn{1}{c}{ \% } & \multicolumn{1}{c}{ Frekuensi } & \% & \\
\hline $20-29$ & 4 & 5,63 & 7 & 9,86 & 11 & 15,49 \\
$30-39$ & 18 & 25,35 & 9 & 12,68 & 27 & 38,03 \\
$40-49$ & 16 & 22,54 & 17 & 23,94 & 33 & 46,48 \\
Jumlah & 38 & 53,52 & 33 & 46,48 & 71 & 100 \\
$\mathrm{X}^{2}$ & & & & & & 3,5119 \\
$\mathrm{X}_{0,05 ; 2}$ & & & & & & 5,991 \\
\hline
\end{tabular}

Sumber: Pengolahan Data Primer, 2018.

Data Tabel 2 di atas memperlihatkan bahwa persepsi PUS tentang KB cukup bervariasi. Namun setelah dilakukan uji statistik menggunakan chi-square dengan hasil $\mathrm{X}^{2}$ hitung 3,5119< $\mathrm{X}^{2}$ Tabel 5,991, ternyata persepsi PUS tentang KB berdasarkan kelompok umur tidak menunjukkan perbedaan yang signifikan. Artinya kelompok umur tidak mempengaruhi persepsi PUS tentang KB.

Temuan ini senada dengan yang dilakukan oleh Mulyani (2016) dalam kajiannya yang berjudul Persepsi
Pasangan Usia Subur Terhadap Program Keluarga Berencana (KB) di Desa Sungai Kuning Kecamatan Singingi Kabupaten Kuantan Singingi bahwa faktor usia tidak mempengaruhi persepsi responden tentang $\mathrm{KB}$.

\section{Persepsi PUS Tentang KB Berdasarkan Pekerjaan}

Pekerjaan PUS dalam penelitian ini yaitu pekerjaan istri dari PUS, meliputi ibu rumah tangga, pegawai dan wiraswasta/ pedangang. 
Tabel 3. Persepsi PUS tentang KB Berdasarkan Pekerjaan.

\begin{tabular}{|c|c|c|c|c|c|c|}
\hline \multirow{3}{*}{ Jenis Pekerjaan } & \multicolumn{4}{|c|}{ Persepsi PUS } & \multicolumn{2}{|c|}{ Frekuensi } \\
\hline & \multicolumn{2}{|c|}{ Positif } & \multicolumn{2}{|c|}{ Negatif } & \multirow{2}{*}{ f } & \multirow{2}{*}{$\%$} \\
\hline & Frekuensi & $\%$ & Frekuensi & $\%$ & & \\
\hline Ibu Rumah Tangga & 25 & 35,21 & 27 & 38,03 & 52 & 73,24 \\
\hline Pegawai & 7 & 9,86 & 1 & 1,41 & 8 & 11,27 \\
\hline Wiraswasta/pedagang & 6 & 8,45 & 5 & 7,04 & 11 & 15,49 \\
\hline Jumlah & 38 & 53,52 & 33 & 46,48 & 71 & 100 \\
\hline & & & & & & 4,3411 \\
\hline $\mathrm{X}_{0,05 ; 2}$ & & & & & & 5,991 \\
\hline
\end{tabular}

Sumber: Pengolahan Data Primer, 2018.

Data Tabel 3 di atas memperlihatkan bahwa persepsi PUS tentang KB cukup bervariasi. Namun setelah dilakukan uji statistik menggunakan chi-square dengan hasil $\mathrm{X}^{2}$ hitung 4,3411 < $\mathrm{X}^{2}$ Tabel 5,991 , ternyata persepsi PUS tentang KB berdasarkan pekerjaan tidak menunjukkan perbedaan yang signifikan. Artinya pekerjaan tidak mempengaruhi persepsi PUS tentang KB. Hal ini berbeda dengan teori yang disampaikan oleh Wood (2013) bahwa peran sosial seperti interaksi dan pekerjaan dapat mempengaruhi persepsi seseorang.

\section{Persepsi PUS Tentang KB Berdasarkan Pendapatan}

Pendapatan dalam penelitian ini yaitu pendapatan suami dan istri yang dikelompokkan menjadi 3 yaitu PUS dengan pendapatan tinggi (>Rp.2.500.000 perbulan), sedang (Rp.1.500.000 s/d Rp.2.500.000 perbulan), dan rendah $(<\mathrm{Rp} .1 .500 .000$ perbulan).

Tabel 4. Persepsi PUS tentang KB Berdasarkan Pendapatan.

\begin{tabular}{|c|c|c|c|c|c|c|}
\hline \multirow{3}{*}{ Pendapatan } & \multicolumn{4}{|c|}{ Persepsi PUS } & \multicolumn{2}{|c|}{ Frekuensi } \\
\hline & \multicolumn{2}{|c|}{ Positif } & \multicolumn{2}{|c|}{ Negatif } & \multirow[b]{2}{*}{$\mathbf{f}$} & \multirow[b]{2}{*}{$\%$} \\
\hline & $\mathbf{F}$ & $\%$ & $\mathbf{f}$ & $\%$ & & \\
\hline Tinggi (>Rp.2.500.000) & 9 & 12,68 & 4 & 5,63 & 13 & 18,31 \\
\hline Sedang (Rp.1.500.000 s/d Rp.2.500.000) & 10 & 14,08 & 9 & 12,68 & 19 & 26,76 \\
\hline Rendah $(<$ Rp.1.500.000) & 19 & 26,76 & 20 & 28,17 & 39 & 54,93 \\
\hline Jumlah & 38 & 53,52 & 33 & 46,48 & 71 & 100 \\
\hline$X^{2}$ & & & & & & 1,6535 \\
\hline $\mathrm{X}_{0,05 ; 2}$ & & & & & & 5,991 \\
\hline
\end{tabular}

Sumber: Pengolahan Data Primer, 2018.

Data Tabel 4 di atas memperlihatkan bahwa persepsi PUS tentang KB berdasarkan pendapatan PUS cukup bervariasi. Namun setelah dilakukan uji statistik menggunakan chi-square dengan hasil $\mathrm{X}_{\text {hitung }}^{2} 1,6535$ $<\mathrm{X}^{2}$ Tabel 5,991 , ternyata persepsi PUS tentang $\mathrm{KB}$ berdasarkan pendapatan tidak menunjukkan perbedaan yang signifikan. Artinya faktor pendapatan tidak mempengaruhi persepsi PUS tentang KB. Hal ini berbeda dengan teori yang disampaikan oleh Mulyana (2016) bahwa pendapatan termasuk 
kedalam faktor yang dapat mempengaruhi persepsi seseorang.

\section{KESIMPULAN}

Berdasarkan hasil penelitian mengenai persepsi PUS tentang keluarga berencana (KB) di Wilayah Pesisir Pantai Kecamatan Pariaman Utara Kota Pariaman, Persepsi PUS tentang KB diperoleh bahwa dari empat variabel yang diuji keberbedaannya yaitu tingkat pendidikan, umur, pekerjaan dan pendapatan, hanya berdasarkan tingkat pendidikan yang berbeda secara signifikan persepsi PUS tentang KB. Artinya tingkat pendidikan mempengaruhi persepsi PUS tentang $\mathrm{KB}$, makin tinggi tingkat pendidikan makin positif persepsinya tentang $\mathrm{KB}$. Responden pada penelitian ini didominasi oleh responden dengan tingkat pendidikan rendah. Untuk itu diperlukannya peningkatan kualitas dan kemudahan dalam pendidikan sehingga masyarakat mampu mengenyam pendidikan tinggi agar persepsi tentang KB kedepannya akan semakin baik. Semakin baiknya persepsi tentang KB akan meningkatkan angka CPR dan menurunkan angka TFR Pariaman terutama di Wilayah Pesisir Pantai Kecamatan Pariaman Utara Kota Pariaman.

\section{DAFTAR PUSTAKA}

Dwi, A dan Andari, D. (2008). Memilih Kontrasepsi Alami dan Halal. Solo: Aqwamedika.

Badan Pusat Statistik (BPS) Kota Pariaman dalam Angka 2017.
(2017). Pariaman: BPS Kota Pariaman.

Harian Haluan. (2016, April 16). BKKBN Sumbar Canangkan Kampung KB. HarianHaluan.com. Diakses dari https://www.harianhaluan.com/ne ws/detail/51879/bkkbn-sumbarcanangkan-kampung-kb.

Indonesia. (2003). Undang-Undang Republik Indonesi tentang Sistem Pendidikan Nasional. (UU RI Nomor 20 Tahun 2003).

Mulyana, D. (2016). Ilmu Komunikasi: Suatu Pengantar. Bandung: Remaja Rosdakarya.

Mulyani, S. (2016). Persepsi Pasangan Usia Subur Terhadap Program Keluarga Berencana (KB) di Desa Sungai Kuning Kecamatan Singingi Kabupaten Kuantan Singingi. JOM FISIP Vol.3 No.1Februari 2016.

Rosyadi, R. (1993). Islam Problema Sex Kehamilan dan Melahirkan. Bandung: Angkasa.

Setiyawan, D. (2015). Hubungan Antara Tingkat Pendidikan dengan Persepsi Para Suami Tentang Program Keluaraga Berencana (Studi Korelasional di RW. 03, Bintara 8, Kelurahan Bintara, Kecamatan Bekasi Barat, Kota Bekasi) (Skripsi).

Siregar, A. (2016). Kebijakan Program Kependudukan, Keluarga Berencana, dan Pembangunan Keluarga dalam Mendukung Keluarga Sehat. Jakarta: Badan Kependudukan dan Keluarga Berencana Nasional (BKKBN). 
Siregar, S. (2013). Metode Penelitian Kuantitatif Dilengkapi dengan Perbandingan Perhitungan Manual \& SPSS. Jakarta: Prenamedia Group.

Suasti, Y dan Mariya, S. (2017). Buku Ajar Demografi. Padang: Sukabina Press.

Sulistyawati. (2011). Pelayanan

Keluarga Berencana. Jakarta: Salemba Medika.

Suratun, S. H., dan Manurung, S. (2008). Pelayanan Keluarga Berencana \& Pelayanan Kontrasepsi. Jakarta : Trans Info Media.

Unit Pelayanan Terpadu Bagian Penyuluh Keluarga Berencana (UPTB.PKB) Kecamatan Pariaman Utara. (2017). Jumlah PUS di Kecamatan Pariaman Utara. Pariaman: UPTB PKB Kecamatan Pariaman Utara.

Wood, J. T. (2013). Komunikasi Interpersonal : Interaksi Keseharian. Jakarta: Salemba Humanika.

Wulandari, T. (2008). Persepsi dan Partisipasi Masyarakat Terhadap Program Keluarga Berencana. Dimensia Vol. 2 No.1, 2008.

Suasti, Y. (2004). Laporan Penelitian fertilitas dan persoalan kesehatan reproduksi di perdesaan Padang Pariaman. Fakultas Ilmu-Ilmu Sosial, Universitas Negeri Padang. 